\title{
Anticuerpos séricos contra la enfermedad de Newcastle e Influenza Aviar en aves rapaces de Chile
}

\author{
Serum antibodies against Newcastle disease and Avian Influenza \\ in birds of pley in Chile
}

\author{
Daniel González-Acuña, ${ }^{1 *}$ Ph.D, Álvaro Gaete, ${ }^{1}$ MV , Lucila Moreno, ${ }^{2}$ Ph.D, Karen Ardiles, ${ }^{1}$ \\ MV, Fabiola Cerda-Leal, ${ }^{3}$ Ph.D, Christian Mathieu, ${ }^{4}$ MV, René Ortega, ${ }^{1}$ Ph.D.
}

\begin{abstract}
${ }^{1}$ Universidad de Concepción, Facultad de Ciencias Veterinarias, Chillán, Chile. ${ }^{2}$ Universidad de Concepción, Facultad de Ciencias Naturales y Oceanográficas, Concepción, Chile. ${ }^{3}$ Universidad del Bío-Bío, Departamento de Ingeniería en Alimentos, Campus Chillán, Chile. Avenida Andrés Bello, S/N. Chillán, Chile. ${ }^{4}$ Servicio Agrícola y Ganadero, Lo Aguirre, Santiago, Chile. *Correspondencia: danigonz@udec.cl
\end{abstract}

Recibido: Septiembre de 2011; Aceptado: Marzo de 2012.

\section{RESUMEN}

Objetivo. Detectar la presencia de anticuerpos séricos sanguíneos contra los virus de la Enfermedad de Newcastle (ENC) e Influenza aviar (IA), para comprender la contribución de las aves silvestres en la transmisión de estos virus en Chile. Materiales y métodos. Se analizaron 63 aves pertenecientes a los órdenes Falconiformes y Strigiformes desde centros de rehabilitación de aves de las zonas central y sur de Chile. Se realizaron las pruebas de inhibición de la hemoaglutinación (IHA) para detectar anticuerpos contra el virus ENC e inmunodifusión en gel agar (IDGA) y ELISA para IA. Resultados. Se detectaron 14 aves positivas (22.2\%) para anticuerpos séricos contra el virus de la ENC. En cambio, no se registraron anticuerpos séricos sanguíneos para el virus de la IA. Conclusiones. La presencia de aves rapaces positivas en los centros de rescate a los anticuerpos séricos contra el virus de la ENC puede ser explicada por el consumo de carne de pollos que han sido vacunados contra ENC o consumo de aves que han adquirido directamente el virus vacunal a través de los distintos procedimientos de administración (aerosoles, bebederos) de la vacuna o por el ingreso a los centros de rescate de aves rapaces migratorias, las que podrían facilitar la diseminación de la infección desde los países de origen, hecho que debe ser investigado.

Palabras clave: Chile, enfermedad de Newcastle, enfermedades virales, influenza aviar, rapaces (Fuente: DeCS). 


\begin{abstract}
Objective. To detect the presence of blood serum antibodies against Newcastle disease (ND) and Avian influenza (AI) viruses, to understand the contribution of wild birds in transmission of these viruses in Chile. Materials and methods. Sixty-three birds belonging to orders Falconiformes and Strigiformes were analyzed from bird rehabilitation centers in central and south-central Chile. Hemagglutination inhibition (HIA) was used to detect antibodies against the ND virus and further AI virus typing was done by agar gel immune-diffusion (AGID) and ELISA. Results. 14 birds we found $(22.2 \%)$ with serum antibodies against ND virus; however, there were no blood serum antibodies to AI virus. Conclusions. Birds of prey from rescue centers have been detected positive for serum antibodies against ND virus. Birds of prey could have become positive via direct consumption of chickens vaccinated against ND or from chickens indirectly exposed to the vaccine through different administrative procedures (aerosols, water troughs) or after the admission of migratory birds to rescue centers, which could facilitate the spread of ND from their countries of origin, and should be investigated.
\end{abstract}

Key words: Chile, influenza in birds, newcastle disease, raptors, virus diseases (Source: DeCS).

\title{
INTRODUCCIÓN
}

La enfermedad de Newcastle (ENC) y la Influenza aviar (IA) son importantes patologías que han sido documentadas en distintas partes del mundo, afectando una gran variedad de especies de animales incluyendo aves, reptiles y mamíferos, inclusive al hombre $(1,2)$. La enfermedad de Newcastle es causada por un virus de la familia Paramyxoviridae, cuyas cepas, han sido clasificadas en cinco grandes grupos basados en la virulencia y el tipo de enfermedad que provocan en las aves de corral (2).

Alrededor de 250 especies de aves son susceptibles al virus de la ENC, como resultado de infecciones naturales o experimentales; hecho que juega un rol importante en la diseminación de este virus (3). Las aves acuáticas son las más resistentes y los reservorios principales del virus; manteniendo cepas avirulentas en el medio ambiente (4). No obstante, varias especies de rapaces son conocidas por ser susceptibles al virus de la ENC, entre las que se mencionan a las familias Falconidae, Accipitridae, Aegypiinae, Cathartidae, Tytonidae y Strigidae de América, Asia y Europa (5-7). Chile, se encuentra libre de la ENC velogénicaviscerotrópica desde 1975 y mantiene una vigilancia y un plan sistemático de vacunación a las aves domésticas y las ponedoras. Esta condición se reconfirmó en el año 2008, tras un brote ocurrido con una cepa mesogénica para pollos, pero filogenéticamente velogénica, en aves silvestres marinas (cormoranes y piqueros) registrado en la zona costera de la ciudad de Constitución (Región del Maule) (8).

El virus de la influenza aviar pertenece a la familia Orthomyxoviridae, al género influenzavirus (9). Se han descrito tres tipos (A, B y $C$ ), clasificados de acuerdo a las diferencias antigénicas de la proteína de la matriz (M) y la nucleoproteína (NP) (9). El virus tipo $A$ es el que puede causar enfermedad en aves y se ha presentado en cerca de 90 especies dentro de 12 órdenes de aves (10). Sin embargo, son las aves acuáticas, particularmente las especies de los órdenes Anseriformes (patos, gansos y cisnes) $(3,11)$ y Charadriiformes (gaviotas) $(11)$ las que constituyen el mayor reservorio (3). Por el contrario, los informes de infección del virus de la IA en aves rapaces son escasos (12). A pesar de este hecho, se han reportado rapaces de los órdenes Falconiformes y Strigiformes positivas al virus de la IA en Asia, África y Europa (11, 12). En Chile, en el año 2002 se produjeron dos brotes, limitados a un sólo plantel en la Región de Valparaíso (Chile). En ambos focos, los aislados obtenidos fueron tipificados como H7N3 de alta patogenicidad. La hipótesis de mayor credibilidad fue la presencia de aves acuáticas silvestres migratorias en las cercanías de uno de los sitios donde se produjo el primer brote (13).

Debido a la importancia de conocer el posible rol de las aves rapaces en Chile como potenciales portadores de virus, el presente estudio tuvo como objetivo detectar la presencia de anticuerpos séricos contra los virus de la enfermedad de Newcastle e Influenza aviar, en ejemplares de los órdenes Falconiformes y Strigiformes, en centros de rehabilitación de aves de las zonas central y centro sur de Chile.

\section{MATERIALES Y MÉTODOS}

Sitio de muestreo y recolección de las muestras. Entre los meses de Octubre de 2004 y Diciembre de 2005, se realizó un muestreo 
dirigido a 63 ejemplares de los órdenes Falconiformes y Strigiformes que ingresaron al Centro de Rescate y Rehabilitación de Fauna Silvestre del campus Chillán de la Universidad de Concepción (36 35'42,21's; $\left.72^{\circ} 05^{\prime} 01,39^{\prime \prime} \mathrm{O}\right)$, al Centro de Rehabilitación de Aves Rapaces de Talagante (33039'59,51"S; $\left.70^{\circ} 55^{\prime} 20,05^{\prime \prime} \mathrm{O}\right)$ y al Zoológico de Quilpué (33002'25,33"S; 71027'05,03"O). A cada ave, se le realizó un examen físico completo, incluyendo peso y condición corporal, presencia de parásitos y signos clínicos de algún tipo de enfermedad. Se extrajeron muestras de sangre de la vena braquial o vena yugular derecha, dependiendo del tamaño del ave. El suero fue separado por centrifugación (2500 rpm por $10 \mathrm{~min}$ ), posteriormente, una cantidad estándar de $0.5 \mathrm{ml}$ de suero fue depositada en tubos microcentrífuga de $1.5 \mathrm{ml}$, los cuales fueron almacenados a $-80^{\circ} \mathrm{C}$ hasta la realización de las pruebas de diagnóstico en el Laboratorio de Virología Pecuaria del Servicio Agrícola y Ganadero (SAG) del complejo Lo Aguirre, Santiago (Chile). Las tres pruebas de diagnóstico realizadas fueron: inhibición de la hemoaglutinación (IHA) para la enfermedad de Newcastle e inmunodifusión en gel agar (IDGA) y la prueba de ELISA-MS para Influenza aviar.

Pruebas de diagnóstico. Inhibición de la hemoaglutinación (IHA). Se realizaron los siguientes procedimientos:

(i) Preparación del lavado de glóbulos rojos de gallo (Gallus gallus), para esto se colocaron de 3 a $5 \mathrm{ml}$ de sangre de gallo con solución de Alsever en un volumen $1: 1$ en un tubo de ensayo de $10 \mathrm{ml}$, completándose con PBS (buffer fosfato salino), luego se centrifugó (10 min/1800 rpm) y se extrajo el sobrenadante. Este procedimiento se repitió en dos ocasiones dejando finalmente sólo los eritrocitos en el tubo de ensayo (14). Los eritrocitos lavados fueron diluidos y llevados a dos concentraciones, $0.5 \%$ (100 $\mu$ l de sangre lavada en $20 \mathrm{ml}$ de PBS) y $10 \%$ (100 $\mu \mathrm{l}$ se sangre lavada en $900 \mu$ l de PBS) (14).

(ii) Tratamiento de suero problema: con el objeto de eliminar las posibles aglutininas que pueden tener los sueros problemas, en una microplaca de 96 pocillos con fondo en forma de "U", se adicionó a cada uno de ellos $100 \mu$ de PBS, 50 $\mu \mathrm{l}$ de cada suero problema y finalmente $50 \mu \mathrm{l}$ de eritrocitos de gallo diluido al $10 \%$ con PBS. La placa se incubó a temperatura ambiente por 30 minutos (14), donde finalmente se observó un botón de eritrocitos en el fondo de cada pocillo.

(iii) Titulación del antígeno: para realizar el procedimiento de titulación se utilizó un virus Newcastle lentogénico (cepa La Sota) de referencia para el Laboratorio de Virología Pecuaria del Servicio Agrícola y Ganadero (SAG) del complejo Lo Aguirre. En una microplaca de 96 pocillos con fondo en forma de "U", se colocaron $50 \mu \mathrm{l}$ de PBS en 2 filas de 12 pocillos. Después, se agregaron $50 \mu \mathrm{l}$ del antígeno en duplicado en los primeros pocillos con una micropipeta multicanal y se realizaron las diluciones del antígeno, seriadas dobles (1:2 hasta $1: 2048)$ hacia la derecha de la microplaca, dejando el último pocillo sin antígeno para que sirva como control de glóbulos rojos. En seguida se agregaron $50 \mu \mathrm{lde}$ glóbulos rojos de gallo diluidos al $0.5 \%$ en cada pocillo, luego se agitó moderadamente la placa para mezclar los reactivos, después se cubrió e incubó a temperatura ambiente por $30 \mathrm{~min}$ hasta cuando se formó un botón distinguible en el fondo del pocillo de control de glóbulos rojos (14). El punto final de la titulación es la dilución más alta del antígeno que cause 100\% de hemoaglutinación, la cual es considerada como una unidad hemoaglutinante (UHA) (14). Para realizar la prueba de inhibición de la hemoaglutinación (IHA) se necesitan 4 UHA en $25 \mu \mathrm{l}(14)$. El punto final de la titulación del antígeno fue de 1:1024 (12.7 ml de PBS con $100 \mu \mathrm{l}$ del antígeno).

(iv) Confirmación de unidades hemoaglutinantes: se debió realizar una confirmación de la UHA a partir del antígeno diluido usado en la prueba, comprobando que existan 4 UHA en $25 \mu \mathrm{l}$. Posteriormente, se agregaron $50 \mu \mathrm{l}$ de PBS a 8 pocillos. Luego se adicionaron 50 $\mu \mathrm{l}$ del antígeno diluido al primer pocillo y se realizaron diluciones dobles hasta el último pocillo. Posteriormente, se agregaron $50 \mu \mathrm{lde}$ glóbulos rojos de gallo al $0.5 \%$ (15). Se dejó una columna control de glóbulos rojos, donde se agregaron a cada pocillo, $50 \mu l$ de PBS y 50 $\mu \mathrm{l}$ de glóbulos rojos de gallo al $0.5 \%$. La placa se incubó a temperatura ambiente hasta que se formó un botón distinguible en el fondo del pocillo de control de glóbulos rojos. El resultado de la confirmación de UHA, se distinguió con una zona nubosa (de aglutinación) en cada pocillo.

(v) Procedimiento de la prueba de IHA: consistió en agregar $25 \mu \mathrm{l}$ del antígeno apropiado (4 UHA en $25 \mu \mathrm{l}$ ), obtenidos de $12.7 \mathrm{ml}$ de PBS con $100 \mu \mathrm{l}$ del antígeno, a todos los pocillos de la microplaca de fondo en forma de "U". Luego se agregaron $25 \mu \mathrm{l}$ de cada suero pre-tratado en los 12 pocillos de la primera fila de la microplaca de fondo en forma de " $U$ " y luego se realizaron diluciones seriadas desde la primera hasta la última columna (14). Además, se incluyó un pocillo control de sueros para detectar 
si persisten aglutininas no específicas. Este pocillo control contenía $25 \mu \mathrm{l}$ de PBS y $25 \mu \mathrm{l}$ del suero tratado, luego se incubaron las placas a temperatura ambiente por 10 a 15 minutos y se agregaron a cada pocillo $50 \mu$ de glóbulos rojos de gallo al $0.5 \%$. Se cubrió la placa y finalmente se agitó e incubó a temperatura ambiente por 25 a 30 minutos para obtener los resultados finales (14).

Inmunodifusión en gel Agar (IDGA). El antígeno (cod. 136-ADV) y el suero control positivo (cod. 433-ADV) fueron suministrados por el laboratorio de referencia Diagnostic Virology Laboratory (DVL), National Veterinary Services Laboratory (NVSL) pertenecientes al United States Department of Agriculture (USDA), Estados Unidos. En una placa Petri con gel agarosa $(0.9 \%)$ se procedió a realizar cinco moldes de siete pocillos cada uno, utilizando una roseta, a los cuales se les extrajo el agar con una bomba de vacío dejando así los pocillos listos para su llenado. Se le adicionaron $32 \mu \mathrm{lde}$ la muestra problema (suero) en pocillos alternos y $32 \mu \mathrm{l}$ del suero control positivo en los posillos alternos restantes. Posteriormente, se incubó la placa Petri a $37^{\circ} \mathrm{C}$ en la cámara de humedad por 24 horas, para finalmente observar la presencia o ausencia de bandas de precipitación en gel agar.

ELISA. Para la realización de la prueba de ELISA, se utilizó el kit Flockchek $囚$, IDEXX para IA (según indicaciones del fabricante).

\section{RESULTADOS}

De los 63 sueros analizados, 14 (22.22\%) resultaron positivos a anticuerpos contra Paramixovirus-1, serotipo causante de la ENC. De éstas, 5 (7.9\%) pertenecieron al órden Falconiforme y $9(14.3 \%)$ a Strigiforme (Tabla $1)$. El detalle de las especies seropositivas fueron: tres águilas (Geranoaetus melanoleucus), un peuco (Parabuteu unicinctus), un traro (Caracara plancus), siete tucúqueres (Bubo magallanicus), un nuco (Asio flammeus) y una lechuza (Tyto alba).

En dos muestras de tucúqueres ( $B$. magallanicus) y una muestra de nuco ( $A$. flammeus) se obtuvieron títulos de 1:16, 1:64 y $1: 32$ respectivamente. Estas tres especies, provenientes del Centro de Rescate y Rehabilitación de Fauna Silvestre del campus Chillán de la Universidad de Concepción, se encontraban vivas sin haber presentado en todo el tiempo que se les mantuvo en dicho centro, algún signo clínico para la Enfermedad de Newcastle.
Tabla 1. Especies seropositivas a la Enfermedad de Newcastle, procedencia y título a la prueba de diagnóstico Inhibición de la Hemoaglutinación (IHA).

\begin{tabular}{lcc}
\hline \multicolumn{1}{c}{ Especies seropositivas } & Procedencia & $\begin{array}{c}\text { Título a } \\
\text { la IHA }\end{array}$ \\
\hline Tucúquere (B. magallanicus) & Chillán $^{1}$ & $1: 16$ \\
Tucúquere (B. magallanicus) & Chillán $^{1}$ & $1: 64$ \\
Nuco (A. flameus) & Chillán $^{1}$ & $1: 32$ \\
Lechuza (T. alba) & Talagante ${ }^{2}$ & $1: 8$ \\
Tucúquere (B. magallanicus) & Talagante $^{2}$ & $1: 16$ \\
Tucúquere (B. magallanicus) & Talagante $^{2}$ & $1: 32$ \\
Tucúquere (B. magallanicus) & Talagante $^{2}$ & $1: 32$ \\
Tucúquere (B. magallanicus) & Talagante $^{2}$ & $1: 32$ \\
Tucúquere (B. magallanicus) & Talagante $^{2}$ & $1: 128$ \\
Águila (G. melanoleucus) & Talagante $^{2}$ & $1: 8$ \\
Águila (G. melanoleucus) & Talagante $^{2}$ & $1: 8$ \\
Águila (G. melanoleucus) & Talagante $^{2}$ & $1: 32$ \\
Traro (C. plancus) & Talagante $^{2}$ & $1: 8$ \\
Peuco (P. unicinctus) & Zoológico de Quilpue & $1: 8$ \\
\hline
\end{tabular}

${ }^{1}$ (C.E.R.E.F.A.S. U. de C. Chillán): Centro de Rescate y Rehabilitación de Fauna Silvestre del campus Chillán de la Universidad de Concepción.

${ }^{2}$ (C.R.A.R Talagante): Centro de Rehabilitación de Aves Rapaces de Talagante.

En el Centro de Rehabilitación de Aves Rapaces de Talagante se obtuvo muestras positivas de las siguientes aves: una lechuza ( $T$. alba) $(1: 8)$; cinco ejemplares de tucúqueres ( $B$. magallanicus) (1:16, $1: 32,1: 32,1: 32$ y $1: 128)$, tres águilas ( $G$. melanoleucus) $(1: 8,1: 8$ y $1: 32$ ) y un traro (C. plancus) (1:8). Las diez aves no presentaron ningún síntoma clínico a la enfermedad al momento de tomar la muestra sanguínea.

Se obtuvo una muestra positiva de peuco ( $P$. unicinctus) (1:8) proveniente del Zoológico de Quilpué. Esta ave no presentaba ningún signo clínico cuando se le extrajo la muestra sanguínea (Tabla 1 ).

Los 63 sueros analizados frente a la presencia de anticuerpos contra el virus de la Influenza aviar resultaron negativos, tanto por la técnica de IDGA como por la prueba de ELISA.

\section{DISCUSIóN}

En el presente estudio se plantean diferentes hipótesis para explicar la seropositividad de las 14 aves. Una de ellas es que los ejemplares seropositivos durante su vida libre o incluso en cautividad, cazaron o recibieron como alimento aves de producción, que se encontraban en un programa de vacunación o aves silvestres 


\section{REVISTA MVZ CÓRDOBA • Volumen 17(3) Septiembre - Diciembre 2012}

que tuvieron contacto con la vacuna de los planteles productivos. Es muy común que en zoológicos y centros de rescate se alimente a las aves rapaces con carne de pollo fresca que procede de planteles avícolas, la cual no es sometida a ningún análisis para ENC antes de ser entregada como alimento. Otra hipótesis es que las aves seropositivas hayan adquirido directamente el virus vacunal a través de los distintos procedimientos de administración (aerosoles, bebederos) de la vacuna en las aves productivas. En Chile, los planteles de producción aviar, utilizan vacunas vivas contra la ENC con las cepas La Sota y Hitchner. Se ha reportado la presencia de la cepa La Sota en lechuzas ( $T$. alba) (6), en halcones peregrino (Falco peregrinus) en Europa (16) y en águila calva (Haliaeetus leucocephalus) y búho (Bubo virginianus) en Estados Unidos (5). Esta cepa se considera no patógena tanto para las aves de corral como para aves silvestres (17). Schettler et al (6) presumen que hay vectores, tales como ratones (vector mecánico), que pueden transportar el virus después de haber tenido algún contacto con aves de producción que se encuentren en un programa de vacunación. Considerando que la lechuza ( $T$. alba) y el nuco (Asio flammeus) consumen casi exclusivamente roedores (18), lo que respalda la teoría propuesta por Schettler et al (6). Otra posibilidad para los reaccionantes en ENC se puede deber al contacto que tuvieron las aves con cepas naturalmente lentogénicas que existen en la naturaleza.

La existencia de aves rapaces migratorias en los centros de rescate, es otra posible causa de la presencia de anticuerpos contra la ENC. Las aves migratorias facilitan la diseminación de la infección desde los países de origen (6). Entre las aves rapaces migratorias se destacan el vari ceniciento (Circus cinereus), el aguilucho (Buteo polyosoma), el aguilucho chico (Buteo albigula), el halcón peregrino (Falco peregrinus) y el águila pescadora (Pandion haliaetus) (18), por lo que se asume que las aves analizadas en el presente estudio pudieron tener contacto con estas aves migratorias, asimismo las aves seropositivas procedentes de un determinado centro de rescate, pudieron contagiarse entre ellas.

Se debe tener en consideración, que las aves rapaces por su condición de depredadoras, poseen la capacidad de alimentarse de otras aves (aves ornitófagas), en especial de aves acuáticas, siendo estas el principal reservorio de la ENC (19). Estudios realizados en el peuquito (Accipiter chilensis), por ejemplo, han encontrado en su dieta aves acuáticas como el churrete (Cinclodes patagonicus) (20); por otro lado el peuco ( $P$. unicinctus) caza palomas adultas y pichones (18).
Es por ello, que otra probable explicación a los presentes resultados es que las aves seropositivas, en algún momento de su vida libre capturaron algún ave acuática u otra ave silvestre infectada con el virus de la ENC.

La ausencia de signos clínicos de la enfermedad en las aves seropositivas analizadas, signos que dependen de la variedad del virus y del hospedador (2), no llama la atención, ya que el período de incubación del virus de la ENC puede variar de 2 a 15 días (2). Infecciones inaparentes han sido observadas en varias especies de rapaces (Strigiformes y Falconiformes) (21); sin embargo, especies de la Familia Accipitridae han mostrado cursos subagudos a crónicos incluyendo desórdenes del sistema nervioso central, diarrea e inapetencia. Curso agudo y fatal ha sido notificado en halcones y búhos (21).

Los títulos de anticuerpos de los individuos muestreados por la prueba de diagnóstico (IHA) tuvieron un rango de $1: 8$ a $1: 128$. En aves de corral, la respuesta obtenida a un virus vacunal lentogénico puede producir títulos en la prueba de IHA de 1:2048 o más (22). Por otro lado, los anticuerpos son generalmente perceptibles en el suero en el plazo desde 6 a 10 días hasta 3 a 4 semanas en pollos ( $G$. gallus) que han tenido la infección y han sobrevivido (2). Aún así, se sigue desconociendo el comportamiento inmunológico en las aves rapaces ante el virus de la ENC, ya que, no se pueden extrapolar los datos de las aves de corral con relación a las aves rapaces (aves silvestres). Queda la incógnita por saber cuál es la cantidad de anticuerpos máximos que pueden ser registrados en las aves rapaces y por cuánto tiempo se mantiene la inmunidad humoral.

El virus de la influenza aviar se encuentra de manera natural en las poblaciones de aves silvestres, donde por lo general se encuentran como subtipos de baja patogenicidad (23). La ausencia de anticuerpos contra la enfermedad de IA en el total de aves analizadas, podría ser explicada por el bajo número de muestras recolectadas, ya que no es un número representativo para descartar la presencia e incidencia de la infección con este virus en las aves rapaces en Chile. Por lo tanto, estos resultados, no nos dan la certeza de que las aves rapaces que habitan el territorio Chileno no estén expuestas a adquirir el virus de la IA, más aún, por la gran cantidad de focos que se han reportado del virus desde fines de 2003 hasta mayo de 2006 principalmente en Asia, África y Europa, con el subtipo H5N1 (HPAI), lo que aumenta el riesgo de diseminación de la enfermedad por el mundo; especialmente cuando la transmisión del virus H5N1 a través 
de regiones extensas es posible con la ayuda de las aves migratorias (24).

Teniendo en consideración que la mayoría de especies de aves domésticas y silvestres parecen ser susceptibles al virus de la IA (25), la presencia de un foco de IA altamente patógena en planteles avícolas, de la Región de Valparaíso, Chile, en el año 2002, sugiere el rol epidemiológico tan importante que juegan las aves de vida silvestre que habitan Chile. En estudios no oficialmente publicados, se ha registrado la existencia de anticuerpos contra el virus de la IA en flamencos (Phoenicoparrus ssp.) en el norte de Chile (Regiones de Arica y Parinacota, Tarapacá y Antofagasta) y en el Zoológico Metropolitano de Santiago (15); además, de un cisne de cuello negro (Cygnus melanocoryphus), en el río Cruces, Región de los Ríos, Chile (4). Se recomienda continuar realizando investigaciones en diferentes especies de aves silvestres para determinar así el rol que juega el virus IA en términos epidemiológicos, tanto en Chile como en otros países.

Los procesos por los cuales pueden aumentar las infecciones emergentes en la vida salvaje pueden ser por alteraciones naturales 0 antropogénicas de los ecosistemas (26). Debido a que las aves rapaces son buenos indicadores de la salud de los ecosistemas (27), se propone seguir investigando las posibles consecuencias que podría ocasionar el virus de la ENC e IA en las aves rapaces, ya que además de ser enfermedades zoonóticas, son un reservorio infeccioso para la producción avícola. Se propone realizar estudios de confirmación (aislamiento viral) de la presencia del virus de Newcastle, para comprobar si el virus se mantiene en la población seropositiva estudiada y así mismo conocer el comportamiento de la cepa aislada in vivo.

\section{REFERENCIAS}

1. Proenca-Módena JL, Santos MacedoI, ArrudaE. H5N1 Avian influenza virus: an overview. Braz J Infect Dis 2007; 11: 125-133.

2. Alexander DJ. Newcastle diseases, other avian paramyxoviruses, and pneumovirus infections. En: Saif YM, Barnes HJ, Fadly AM, Glisson JR, McDougald LR, Swayne $D E$, Editores. 11 ed. USA:Iowa: Diseases of poultry; 2003.

3. Sa'idu L, Baba Tekdek L, Ayuba Abdu P. Prevalence of Newcastle disease antibodies in domestic and semi-domestic birds in Zaria, Nigeria. Vet Arhiv 2004; 74:309-317.

4. Alvarado LA. Prospección de enfermedades virales, Mycoplasma gallisepticum y Salmonella sp. en cisnes de cuello negro (Cygnus melanocoryphus, Molina. 1782) en el santuario de la naturaleza "Río Cruces", Valdivia [Tesis de grado]. Chile: Universidad Austral de Chile; 2004.

5. Jindal N, Yogesh C, Primus A, Redig P, Goyal $\mathrm{S}$. Isolation and molecular characterization of Newcastle Disease Viruses from raptors. Avian pathol 2010; 39:441-445.

6. Schettler E, Fickel J, Hotzel H, Sachse K, Streich WJ, Wittstatt $U$ et al. Newcastle Disease Virus and Chlamydia psittaci In free-living raptors from eastern Germany. J Wild Dis 2003; 39:57-63.
7. Choi K, Lee E, Jeon W, Nah J, Kim Y, Lee M et al. Isolation of a recent Korean epizootic strain of Newcastle Disease Virus from Eurasian scops owls affected with severe diarrhea. J Wild Dis 2008; 44: 193-198.

8. Jeria J, Rivera A, Max V, González Á, Moreno $V$, Jara $C$, et al. Informe epidemiológico final: detección de un brote de la enfermedad de Newcastle (ENC) en aves marinas, en la zona costera de Constitución, Región del Maule, Chile 2007. [en línea] 2009. [fecha de acceso 9 de junio de 2009]. URL Disponible en: http://www2.sag.gob.cl/ Pecuaria/bvo/BVO_9_I_semestre_2009/ articulos/informe_final_ENC_2007.pdf

9. Hindiyeh $M$, Levy $V$, Azar R, Varsano N, Regev $L$, Shalev $Y$ et al. Evaluation of a multiplex real-time reverse transcriptase PCR assay for detection and differentiation of influenza viruses $A$ and $B$ during the 2001-2002 influenza season in Israel. J ClinMicrobiol 2005; 43: 589-595.

10. Tracey JP, Woods R, Roshier D, West P, Saunders GR. The role of the wild birds in the transmissions of avian influenza for Australia: an ecological perspective. EMU 2004; 104: 109-124. 
11. Ellis $\mathrm{T}$, Dyrting $\mathrm{K}$, Wong $\mathrm{C}$, Chadwick B, Chan C, Chiang M, et al. Analysis of H5N1 avian influenza infections from wild bird surveillance in Hong Kong from January 2006 to October 2007. Avian Pathol 2009; 38:107-119.

12. Manvell RJ, McKinney $P$, Wernery $U$, Frost K. Isolation of a highly pathogenic influenza A virus of subtype H7N3 from a peregrine falcon (Falco peregrinus). Avian Pathol 2000; 29: 635-637.

13. Max V, Herrera J, Moreira R, Rojas $H$. 2006. Avian influenza in Chile: a successful experience. Avian Dis 2006; 51:363-365.

14. Senne D. Hemagglutination-Inhibition test to detect serum antibodies to avian Paramixoviruses. Testing protocol No. AVPR00800.04. Ames (USA): Dept. of Agriculture Animal (USDA) Animal and Plant Health Inspection Service (APHIS); 2005.

15. Torregrosa M. Estudio serológico de enfermedades virales en flamencos del norte de Chile [Tesis de grado]. Santiago de Chile: Universidad Mayor; 2003.

16. Manvell RJ, Wernery U, Alexander DJ, Frost KM. Microbiology. Newcastle diseases (avian pmv-1) viruses in raptors. En: Lumeij JT, Remple JD, Redig PT, Lierz M, Cooper JE, Editores. Raptor biomedicine III including Bibliography of diseases of birds of prey. Zoological. Florida: USA; 2000.

17. Zanetti F, Berinstein A, Pereda A, Taboga O, Carrillo E. Molecular characterization and phylogenetic analysis of Newcastle Disease Virus isolates from healthy wild birds. Avian Dis 2005; 49:546-550.

18. Pavez E. Descripción de las aves rapaces. In: Muñoz A, Rau J, Yánez J, editores. Aves rapaces de Chile. Valdivia (Chile): CEA ediciones; 2004.
19. Quinn PJ, Markey BK, Carter ME, Donnelly WJ, Leonard FC. Microbiología y enfermedades infecciosas veterinarias. Zaragoza (España): Acribia SA; 2002.

20. Figueroa RA, Corales ES, Alvarado S. Diet of the Red-backed hawk (Buteo polyosoma) in a forested area of the Chilean patagonia and its relation to the abundance of rodent prey. Hornero 2003; 18:43-52.

21. Schettler E, Langgemach $T$, Sömmer $P$, Streich J, Frölich K. Seroepizootiology of selected infectious disease agents in freeliving birds of prey in Germany. J Wild Dis 2001; 37:145-152.

22. Alexander, D.J. Newcastle disease, Gordon Memorial Lecture. Newcastle disease. $\mathrm{Br}$ Poult Sci 2001; 42:5-22.

23. Clark L, Hall J. Avian influenza in wild birds: status as reservoirs, and risks to humans and agriculture. Ornithol Monograhs 2006; 60:3-29.

24. Feare CJ. The role of wild birds in the spread of HPAI H5N1. Avian Dis 2007; 51:440-447.

25. Buscaglia C. Influenza aviar. InVet 2004; 6:1.

26. Williams ES, Yuill T, Artois M, Fischer J, Haigh SA. Emerging infectious diseases in wildlife. Rev Sci Tech 2002; 21:139-157.

27. Jaksic F. Prologo. In: Muñoz A, Rau J, Yánez J, editores. Aves rapaces de Chile. Valdivia (Chile): CEA ediciones; 2004. 